\title{
Atividades interativas com o uso de tecnologias digitais como mediadoras da aprendizagem no ensino fundamental
}

\author{
Juliana Silva Arruda ${ }^{1}$, José Aires de Castro Filho ${ }^{2}$, Liliane Maria Ramalho de \\ Castro Siqueira $^{3}$, Rayssa Araújo Hitzschky ${ }^{1}$, Ellen Lacerda Carvalho Bezerra ${ }^{1}$. \\ ${ }^{1}$ Faculdade de Educação - Universidade Federal do Ceará (UFC) - Campus do Pici - \\ Rua Waldery Uchôa, 01 - Benfica, Fortaleza - CE, 60020-060 - Fortaleza-CE \\ ${ }^{2}$ Instituto UFC Virtual - Universidade Federal do Ceará (UFC) - Campus do Pici - \\ Bloco 90110 andar, Fortaleza-CE
}

${ }^{3}$ Faculdade de economia, administração, atuária, secretariado, contabilidade e finançasFEAAC Av. da Universidade, 2486 - Benfica - CEP 60020-180 - Fortaleza - CE.

\footnotetext{
julianarruda24@gmail.com; aires@virtual.ufc.br; ramalholiliane@yahoo.com.br; hitzschkyrayssa@gmail.com; alinefbrito@gmail.com; ellenlcb7@gmail.com
}

\begin{abstract}
The school must keep pace with the changes brought about by technological advances and be attentive to new educational possibilities. These resources enable interaction in group activities, in the exchange of ideas and opinions or in the search for other realities. This study aimed to analyze how the computer, through digital resources, can mediate the emergence of the interaction. A qualitative, interpretive approach was used. The research technique involved participant observation and as instruments of data collection, videos and field journals. The results pointed out that the resources, together with the interaction between peers, facilitate the learning, making possible performances and postures of authorship.
\end{abstract}

Resumo. A escola deve acompanhar as mudanças advindas dos avanços tecnológicos e ficar atenta às novas possibilidades educacionais. Estes recursos possibilitam a interação nas atividades em grupo, na troca de ideias e opiniões ou para a pesquisa de outras realidades. Este estudo teve por objetivo analisar como o computador, por meio de recursos digitais, pode mediar a emergência da interação. Foi utilizada uma abordagem qualitativa, com caráter interpretativo. A técnica de pesquisa envolveu a observação participante e como instrumentos de coleta de dados, vídeos e diários de campo. Os resultados destacaram que os recursos, aliados à interação entre pares, facilitam a aprendizagem, possibilitando atuações e posturas de autoria. 
VII Congresso Brasileiro de Informática na Educação (CBIE 2018)

Anais do XXIV Workshop de Informática na Escola (WIE 2018)

\section{Introdução}

Há uma relação entre tecnologia e sociedade, considerando que esta última se desenvolve a partir de um sistema complexo de interação, compreendendo o avanço da ciência e as transformações tecnológicas [CASTELLS, 1999].

A disseminação das tecnologias, como a Internet e os dispositivos móveis, faz com que recursos tecnológicos sejam inseridos em ambientes de aprendizagem, tornando a relação entre a tecnologia e a educação essencial nos processos de ensino e de aprendizagem. $\mathrm{O}$ uso das tecnologias digitais nos meios escolares suscita a investigação do desempenho em sala de aula, o desenvolvimento das habilidades, a motivação dos aprendentes e a participação individual e em grupo [RESTA; LAFERRIÈRE, 2007].

Esse cenário torna-se um desafio para os educadores, haja vista que as informações da rede, constituídas a partir dos recursos tecnológicos, não estão em meios físicos, como livros; possuem conteúdos dinâmicos e originados em processos, como a interação. Considera-se, ainda, que o momento atual é cercado de informações quase instantâneas, principalmente devido à Internet. Torna-se imprescindível promover um incentivo à análise das imagens e dos conteúdos divulgados, para que não ocorra apenas a disseminação indiscriminada, mas que esse processamento possa ser pensado, refletido e criticado.

O interesse do estudo está focado na compreensão dos processos de aprendizagem mediados pela tecnologia. A pesquisa originou-se da seguinte questão: Como as atividades interativas envolvendo o uso de recursos digitais podem favorecer a aprendizagem de alunos do Ensino Fundamental de uma escola pública?

A partir dessa problemática, define-se o objetivo geral do estudo, que é investigar a relação entre a interação e a aprendizagem dos educandos do Ensino Fundamental quando realizam atividades com o suporte de tecnologias digitais. Como objetivos específicos, propõem-se: 1) descrever as características do contexto de interação e 2) identificar atividades interativas com o uso de recursos digitais que possibilitem a aprendizagem.

Esta pesquisa pretende trazer subsídios para facilitar o processo de interação estudantil utilizando as tecnologias como recurso mediador. Justifica-se o estudo considerando que os recursos digitais, a cada dia, demonstram-se como uma realidade da educação brasileira, no entanto, muitas vezes, sendo desconhecido seu verdadeiro potencial e a intensidade de suas contribuições para a aprendizagem dos alunos.

Na próxima sessão será discutida a base teórica do estudo, seguida pela discussão prática entre mediação, interação, aprendizagem e tecnologia, os procedimentos metodológicos, resultados e discussões, fechando com as considerações finais.

\section{O processo de aprendizagem sob o viés das interações sociais}

Para Vygotsky, as mudanças que ocorrem no ser humano ao longo do seu desenvolvimento possuem gênese nos meios culturais, sociais e históricos. O início dos pensamentos abstratos e conscientes dá-se através dos processos interacionistas do sujeito com o ambiente social [NASCIMENTO, 2007].

Segundo Suanno [2003], a influência do contexto exterior no interior dos seres humanos deve ser analisada a partir dos processos de interações entre estes. A teoria 
VII Congresso Brasileiro de Informática na Educação (CBIE 2018)

Anais do XXIV Workshop de Informática na Escola (WIE 2018)

vygotskyana considera a aprendizagem a partir da história social. As relações sociais são enfatizadas como fator essencial para a aprendizagem [MEIRA; SPINILLO, 2006].

Meira e Lerman [2009] consideram que o aprendizado é um processo não estático que ocorre de maneira processual entre os integrantes dessa relação. A aprendizagem é caracterizada como um processo coletivo, surgindo das relações entre educandos, educadores e pares, e não como meio individual do aluno. Compreende-se, então, a aprendizagem como um sistema dinâmico, desenvolvendo-se não a partir de um conhecimento pré-definido, mas, de forma relacional, entre aprendentes-professor e aprendentes-pares.

Há uma estreita relação entre as atividades que envolvem os signos e a linguagem na interação dos seres humanos, haja vista que os signos agem como mediadores da linguagem, representando elementos da cultura. Por exemplo, mesmo sem ver uma caneta, o ser humano consegue relacionar o nome ao objeto. Dessa forma, os sujeitos se constituem a partir da interação, não podendo ser de maneira nenhuma semelhante ao que outra pessoa está constituindo e nem por ela mesma em outras situações [VYGOTSKY, 1994].

Segundo Colaço [2004], os fatores linguísticos estão associados às ações sociais e têm como origem as práticas de diálogos, que se efetivam na interação, apresentando atuações mediadoras nesse processo. Representa-se a interação a partir dos estudos de Colaço [2001], que compreende a interação não apenas nas relações sujeito-sujeito(s), mas também como um processo básico do indivíduo como ser social e historicamente constituído por uma realidade construída por ele próprio, no âmago dos conteúdos que são mediados pelas interações e no contexto simbólico dessa troca, originando condições de aprendizagem. Esse espaço simbólico de intercâmbio pode viabilizar a aprendizagem e tem um papel preponderante no contexto do ensino, no qual docentes e alunos se envolvem e compartilham dessa construção.

Pretende-se analisar como se concebe a interação em um grupo de aprendentes que realizam atividades interativas, utilizando a tecnologia como recurso. Para tanto, o próximo tópico discorre sobre a tétrade: mediação, interação, aprendizagem e tecnologia.

\section{Mediação, interação, aprendizagem e tecnologia: Estudos Anteriores}

Com a globalização das informações, na atualidade, temas como compartilhamento e relações políticas e sociais surgem cada dia com mais frequência na sociedade. Não há mais limites espaciais para que diferentes realidades e contextos se cruzem e troquem informações. E é nesse universo que o tema interação torna-se frequentemente mais visível, maximizando suas áreas de investigação e interesse, e envolvendo diferentes campos de pesquisa, como Educação, Psicologia e Linguística.

$\mathrm{Na}$ busca do entendimento da aprendizagem, por diferentes campos de pesquisa, o termo interação acaba sendo utilizado de maneira confusa, sendo, portanto, necessário considerar esse conceito com precisão e compreender que ele precede o avanço das TIC. Santiago et al. [2016] argumentam que a inclusão digital se insere no contexto social do processo educacional, e por isso, deve ser considerada, abordada e implementada. Sendo assim, o planejamento e a execução das atividades são imprescindíveis na inclusão das tecnologias digitais na educação para que haja a participação de toda a sociedade [RODRIGUES et al., 2011]. 
VII Congresso Brasileiro de Informática na Educação (CBIE 2018)

Anais do XXIV Workshop de Informática na Escola (WIE 2018)

Silva [2014] desenvolve seu estudo a partir da concepção de que o trabalho coletivo entre aprendentes proporciona a atuação de mediadores, por meio do relacionamento entre pares ou com adultos, possibilitando a aprendizagem e acarretando o desenvolvimento dos educandos. Sendo assim, sistematiza-se a relevância da teoria vygotskyana, essencialmente o conceito de mediação, como base importante para as atividades educacionais, de forma que esta influencia diretamente a aprendizagem, principalmente tarefas colaborativas.

Del Rio e Álvarez [1998] também enfatizam os aspectos coletivos da aprendizagem como mediadores essenciais para a formação e o desenvolvimento. Dessa forma, a atividade humana pode ser definida a partir de ferramentas culturais. "Os seres humanos são basicamente animais que usam signos e as formas de ação que desenvolvem, especialmente o falar e o pensar, envolvem uma combinação não redutível de um agente ativo e uma ferramenta cultural." [WERTSCH, 2010, p. 123].

Para Góes [2001], a aprendizagem também emerge das relações conflituosas, sendo mediada pelas pessoas com as quais o aluno convive, mas não somente por elas: os mediadores ampliam-se para diferentes relações sociais, desenvolvidas em variados contextos.

Frade e Meira [2012] consideram a interação um processo das relações sociais, cujo produto é a aprendizagem, através de um ambiente ou situações sociointeracionais. Os discursos dos alunos e professores contribuem para a aprendizagem juntamente com a receptividade e a disponibilidade do professor na facilitação desse processo. Meira e Lerman [2009] complementam esse pensamento, afirmando que são várias as formas de interação no ambiente educacional que levam ao sucesso dos processos de ensino e de aprendizagem.

Segundo Silva [2000], as TIC podem potencializar a interação, esta tem origem na física, e vem sendo utilizada em outras áreas, e especificamente na Informática, definindo-se a partir da interferência do espectador no processo, atuando como autor, criando e recriando. A intensa capacidade de conexão com a internet através dos dispositivos móveis, como: smartphones, tablets ou netbooks, e possibilitam a disponibilidade de diferentes tipos de recursos que facilitam a autoria e criatividade, através da promoção da participação, do compartilhamento e dos diálogos [NASCIMENTO; CASTRO-FILHO, 2015].

Peres e Meira [2009] analisam que, apesar dos sistemas de regulação serem característicos dos processos de interfaces, as TIC também podem promover o encontro entre os aprendentes, considerando a interação uma característica especificamente do ser humano.

Os pesquisadores afirmam, ainda, que as relações que envolvem o diálogo estão contidas na interação, presencial e a distância. As atividades propostas que utilizam os meios computacionais constroem enunciados para promover a relação dialógica. Dessa forma, o aprendente está inserido em uma interação social e também cultural, e suas relações dialógicas com pares e/ou professores podem ser estabelecidas com o uso da tecnologia.

A seguir, serão apresentados o contexto em que a pesquisa foi realizada, assim como os detalhes dos instrumentos de produção de dados e procedimentos de análise para verificação dos objetivos iniciais, relacionando-os aos estudos teóricos e empíricos.

\section{Procedimentos Metodológicos}


O estudo apresenta natureza qualitativa, a partir da explicitação das observações e das estratégias utilizadas pelos discentes, utilizando-se da análise e da interpretação das mesmas. Segundo Meira [1994], a análise qualitativa de processos como a aprendizagem e a interação é complexa, devido o envolvimento com transformações sutis e breves de gestos e diálogos.

O presente estudo foi estruturado a partir do contexto do projeto EDigital, que teve parceria do Endesa e da Companhia Energética do Estado do Ceará. Este projeto teve como principal meta desenvolver competências por meio do programa de formação da comunidade escolar, para a inclusão e o uso das tecnologias digitais na Educação. $\mathrm{O}$ projeto EDigital teve início em 2013, apresentando os seguintes segmentos de formação: i) formação de professores; ii) formação de alunos monitores e iii) desenvolvimento de projetos que envolviam a sustentabilidade.

A formação dos docentes envolveu a apropriação tecnológica, que se caracterizou pelo processo de apresentação de recursos digitais e teve como principal meta compartilhar com a comunidade escolar a aplicação da tecnologia na Educação. A formação de alunos monitores foi caracterizada pela inclusão digital do discente, que se inseriu no projeto de forma voluntária. A constituição de alunos monitores buscou promover a aprendizagem, por meio da interação e da tecnologia, e culminando com o acompanhamento e auxílio destes alunos às aulas com uso das TIC, juntamente, com a equipe docente da escola.

Durante o desenvolvimento do estudo, foi proposto aos aprendentes um projeto com base nos seguintes temas: educação ambiental, consciência crítica de sustentabilidade e das tecnologias. Foram realizadas atividades que proporcionassem a interatividade e o trabalho em grupo como postagens na rede social Facebook, discussões de grupo, produção de vídeos, aula em campo. O trabalho foi desenvolvido no Laboratório de Informática Educativa - LIE da escola e também em seus arredores, aproveitando o caráter móvel de ferramentas como netbooks, tablets e smartphones.

\section{Resultados e Discussões}

Os resultados desse estudo surgiram da transcrição de vídeos e de áudios analisados após a coleta de dados. Ressalta-se que os diálogos foram transcritos de forma literal, razão pela qual podem apresentar alguns erros ortográficos, gramaticais e de concordância. Em seguida, foram selecionados exemplos e situações, além de registros fotográficos e fragmentos de vídeos, que embasassem cada categoria.

Os resultados foram analisados de acordo com categorias, no momento da análise dos dados. A primeira categoria - Interação entre pares - é compreendida a partir do diálogo de dois ou mais alunos, tendo sido estabelecido um espaço dinâmico para conversação, quando os aprendentes tiveram a oportunidade de discutir questões. Outro fator considerado nessa categoria diz respeito aos conceitos ou conhecimentos sobre os quais o aluno ainda não tinha compreensão ou apresentava um entendimento diferente, e que a partir da conversa com o colega, negociavam juntos um novo conceito comum a todos.

A segunda categoria - Interação com alguém mais experiente - envolveu contribuições e assistência de alguém mais experiente, contribuindo para a facilitação da aprendizagem. Assim, foram considerados os diálogos dos alunos com alguém mais experiente que poderia ser os pesquisadores e os próprios colegas. As duas categorias serão discutidas a seguir. 
VII Congresso Brasileiro de Informática na Educação (CBIE 2018)

Anais do XXIV Workshop de Informática na Escola (WIE 2018)

\subsection{Interação entre pares}

Considera-se como interação entre pares quando se estabelecem, nas entrelinhas, conversações e diálogos estabelecidos entre os alunos, demonstrando a aprendizagem como um espaço dinâmico que se constitui a partir dessa interação.

Quando o aluno M postou a Figura 1 na rede social, o aluno R pesquisou o que ele poderia criar. Então, disse que queria fazer um gerador de energia usando água sanitária. Outros alunos sugeriram oficinas de material reciclado na escola, corroborando que a imagem postada, utilizando a tecnologia como recurso, facilitou $\mathrm{R}$ na busca de outras ações sustentáveis.

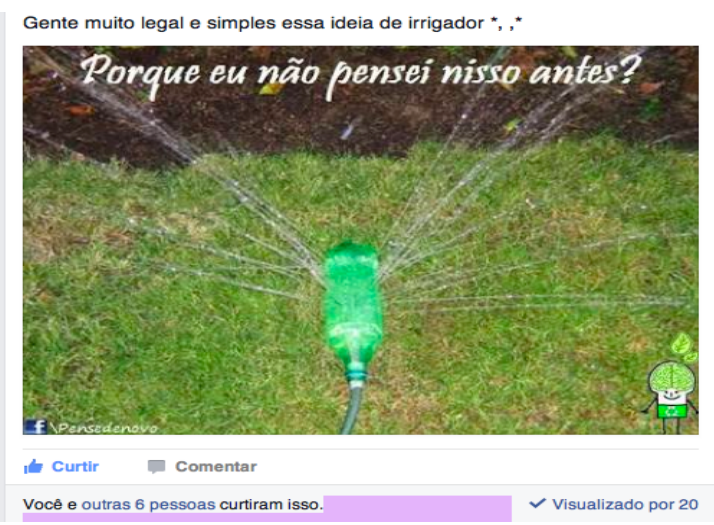

Figura 1 - Imagem postada no Facebook pelo aluno.

Outro momento em que se evidenciou a interação entre pares foi durante a aula de campo. Os alunos foram distribuídos em grupos e optaram por escolher nomes que os identificassem. Então, cada turma se reuniu para formular a sua denominação. Durante a conversação, percebeu-se que eles procuraram negociar entre si, demonstrando interação. Outro aspecto que demonstrou a facilitação na aprendizagem dos conteúdos propostos diz respeito ao fato do nome da turma estar diretamente relacionado aos temas estudados durante a formação, como: FBI Nature. Ressalta-se, ainda, que não foi apresentada pelos pesquisadores nenhuma sugestão; os alunos relacionaram sua identificação ao que tinha sido visto, conseguindo expressar o que haviam conversado, como a imagem das plantas e a cor verde relacionada à sustentabilidade.

O suporte da tecnologia facilitou a realização das atividades em grupo, em que os membros trabalharam colaborativamente, utilizando o computador e elegendo uma meta comum. Pode-se perceber isso nas pesquisas em sites de busca, em que os alunos ampliaram a visão que tinham dos conceitos, na elaboração de textos colaborativos, conseguindo produzi-los com o editor, além da produção de vídeos, quando interagiram com os seus pares. Corroborando com essa constatação, Lipponen [2002] afirma que a interação entre sujeitos na realização de uma atividade, utilizando a tecnologia como recurso, viabiliza a aprendizagem conjunta, haja vista que facilita a troca de conhecimentos.

O exemplo 1 é a transcrição de uma interação que ocorreu através da rede social Facebook. Primeiramente, foi postado um texto sobre a conceituação dos 3R na página da rede social e os alunos comentaram, acabando por construir um texto como produto final, feito em grupo e com informações que se complementam. 
VII Congresso Brasileiro de Informática na Educação (CBIE 2018)

Anais do XXIV Workshop de Informática na Escola (WIE 2018)

Exemplo 1 - Construindo o conceito de 3R

Aluno N: Reutilizar é o uso de um produto mais de uma vez, independentemente da mesma função ou não.

Aluno M: Reciclar é ato de usar objetos como garrafas pet, latas.

Aluna A: Podendo transformar em novos objetos.

Aluna L: Reduzir e reduzir o consumo de coisas necessárias no nosso dia a dia. Aluna A: E acumular menos lixo.

No exemplo 1, foi exibido um vídeo para os aprendentes sobre o tema 3R. Logo após a exibição, perguntou-se aos alunos qual a definição dos $3 \mathrm{R}$, que perpassa um conceito utilizado para designar três ações sustentáveis relacionadas ao tratamento do lixo, que são: Reduzir, Reutilizar e Reciclar. Essa atividade proporcionou vivências de diálogo e troca de ideias. Após essa discussão, a definição foi novamente solicitada, agora pelo Facebook, e eles conseguiram ir além do que foi proposto, constituindo um texto coletivo, em que um estudante complementava o pensamento do outro.

Observa-se que o aluno $\mathrm{N}$ introduziu um conceito sobre Reutilizar, $\mathrm{M}$ completou, seguido das alunas A e L, e A finalizou o conceito. Os aprendentes conseguiram construir um texto de forma colaborativa, transpondo a exposição de um pensamento isolado e individual sobre o conceito de 3R para uma produção coletiva e socializada.

Demonstra-se, portanto, o desenvolvimento da aprendizagem através da apresentação de um conceito até então desconhecido, tendo em vista que foram questionados sobre a temática antes da visualização do vídeo. Posteriormente, os alunos habituaram-se com o tema e logo trabalharam com situações do cotidiano escolar envolvendo a sustentabilidade, por meio de discussões em grupo. A partir da construção de um colega, deram continuidade e constituíram um texto lógico e contextualizado.

\subsection{Interação com alguém mais experiente}

Caracteriza-se a discussão com alguém mais experiente quando é estabelecido um diálogo, e a partir dessa conversação, o participante que ainda não conseguia entender um conceito passa a compreendê-lo. Outro aspecto importante da aprendizagem é que ela também se relaciona com o desenvolvimento de uma compreensão conjunta sobre algo, ou seja, duas ou mais pessoas com concepções distintas começam, por meio de uma conversa, a ter uma compreensão comum, a partir de mudanças conceituais possibilitadas pela interação.

No diálogo do exemplo 2, os alunos produziam slides sobre os resultados das pesquisas da aula de campo, utilizando a ferramenta de edição de apresentações do Google Drive. A atividade ocorreu de forma presencial e em grupo.

Exemplo 2 - Constituição do vídeo.

Aluna A: Vou colocar outra foto, tira essa e coloca essa. Ele vai demorar meia hora só pra mudar. É só recortar e colar.

Aluna L: Qual a página que você tá aí ? Qual o link? Vou entrar também.

Aluna A: Deixa eu ver, é só ir em editar. Tá dando certo, gente?

Aluno C: Tem como colocar efeito pra não ficar passando direto.

Aluna A: É transição.

Aluno M: Você pode colocar alguns slides para serem automáticos e outros não.

Aluno C: Ah, certo, entendi.

Aluna A: Bota aí aquela notícia que a gente leu naquela reportagem. Falta de conscientização, vou colocar aqui. E a gente coloca o que no começo?

Aluno C: Pronto, agora podemos colocar o tema, vamos.

Aluna L: Não, agora não, vamos selecionar primeiro as fotos. 
VII Congresso Brasileiro de Informática na Educação (CBIE 2018)

Anais do XXIV Workshop de Informática na Escola (WIE 2018)

Aluna A: Isso também acho. Olha essa mesmo com a lixeira aí, um monte de retardado coloca o lixo no chão, vê essa imagem.

Aluna L: Vai, aluno C, agora é sua vez, coloca o tema.

Os alunos estabeleceram uma conversação envolvendo a produção dos slides, em que cada um contribuiu a partir do uso da ferramenta. O espaço dinâmico ocasionado pelo diálogo destaca que um aluno orientou outro, quando a aluna A consegue relacionar a notícia vista anteriormente, por meio da conversa. Ao mesmo tempo, ela pergunta sobre $\mathrm{o}$ andamento da atividade e, ainda, faz referência à outra reportagem, sugerindo-a para a produção. Observa-se a troca de conhecimento, quando o aluno $\mathrm{C}$ não sabe o que é transição e os alunos A e M explicam e, em seguida, ele já consegue aplicar na prática. A partir desse exemplo, percebe-se que alguém mais experiente pode ser um colega e que os significados puderam encontrar propósitos, implicando na possibilidade de aprendizado inexistentes antes do evento, e que a partir do desenvolvimento da atividade, foram produzidas novas formas de comunicação.

O próximo exemplo apresentou a discussão síncrona com alguém mais experiente, no caso, uma aluna, que desencadeou toda a discussão. Foi estabelecida uma discussão pelo Facebook, criando uma comunicação assíncrona, haja vista que os alunos formaram uma sequência de comentários em tempos e momentos distintos. No caso, dois participantes leram uma postagem sobre a cobrança de multa para quem coloca lixo na rua. Primeiramente, o aluno E concordou, achando que a cobrança de multa era devida, porque as pessoas iriam aprender. No entanto, a aluna I discordou e registrou seu questionamento, afirmando que a melhor saída era a conscientização do cidadão através do trabalho comunitário. O aluno $\mathrm{E}$ mudou de opinião a partir do diálogo on-line com a colega, demonstrando aprendizagem, já que houve constituição de novos conceitos a partir da interação entre pares, utilizando a rede.

Exemplo 3 - Mudança de conceito.

Aluno E: Sim, pois algumas pessoas só aprendem quando dói no bolso. Aluna I: Eu não concordo. Considerei uma forma de "extorquir o bolso" pela sua ignorância, ele não tem culpa; e ele acaba pagando por isso. $\mathrm{O}$ trabalho comunitário como punição é bem mais conscientizador.

Aluno E: Realmente, você está certa. Um dia, quando não houver mais corrupção, saberemos para onde vai o dinheiro da multa.

Aluna I: Esse dia, teremos que esperar sentados, se é que vai chegar. Porque, enfim, a corrupção não existe apenas na política; ela está grudada no cotidiano. Aluno E: Antes de ouvir a opinião da aluna I, eu não pensava assim, mas depois comecei a entender que não podemos confiar em um país tão corrupto.

Complementando a discussão das categorias do estudo, considera-se que as atividades interativas proporcionam um espaço semiótico que ofereceu aos aprendentes um ambiente propício para sua atuação como autores do próprio conhecimento.

\section{Considerações finais}

O estudo relacionou a aprendizagem entre os alunos com base em questões teóricas, objetivando responder à pergunta inicial da pesquisa: Como as atividades interativas envolvendo o uso de recursos digitais podem favorecer a aprendizagem de alunos do Ensino Fundamental de uma escola pública?

As filmagens demonstraram os gestos e os diálogos dos alunos, facilitando a percepção quanto à interação, assim como Vygotsky [1994] preconizou a interação social como condição essencial para a aprendizagem. Destacam-se, ainda, as contribuições do 
VII Congresso Brasileiro de Informática na Educação (CBIE 2018)

Anais do XXIV Workshop de Informática na Escola (WIE 2018)

estudo para a prática pedagógica, trazendo inovadores recursos para o ensino, dentre eles, as tecnologias digitais. Respondeu, assim, ao objetivo geral que foi investigar a interação dos educandos do Ensino Fundamental quando realizam atividades com o suporte das TIC.

As considerações finais são elencadas e relacionadas às categorias utilizadas na análise dos dados e a partir dos dois objetivos específicos da pesquisa. Os pesquisadores, que também atuaram como formadores da turma, oportunizaram vivências promovedoras de interações, além de agirem como um canal de assistência e também de desafio por meio de frequentes questionamentos e de atividades que permitiram a concretização da mediação e da interação presente nesta pesquisa, por meio das categorias que foram: interação entre pares e interação com alguém mais experiente.

O papel exercido pelos pesquisadores demonstrou a função mediadora e crucial do professor ao fomentar momentos de discussão junto aos seus alunos, promovendo situações desafiadoras que favoreceram a mudança de postura dos discentes para uma função ativa, onde eles puderam atuar, entrevistar, dar sugestões e produzir.

Com relação ao objetivo específico de identificar atividades interativas com o uso de recursos digitais que possibilitem a aprendizagem, o ambiente em que a mediação foi facilitada desenvolveu-se a partir de atividades que ofereceram aos alunos a sua participação no processo educacional de forma autoral. As opiniões e sugestões eram aceitas e incentivadas, constituindo a conversação entre os grupos, além de promover o protagonismo.

O tema sustentabilidade, por ser atual e discutido no meio cultural, também criou esse ambiente propício ao desenvolvimento, visto que foi passível de discussões. Os discentes mudaram o seu espaço por meio de posturas ativistas, além de agir com autonomia para realizar mudanças e sugerir elementos que julgavam facilitar o processo e a sua caminhada.

Dessa forma, a interação emergiu a partir do momento em que os discentes perceberam que poderiam atuar como autores dos seus processos de aprendizagem, sendo produtores do próprio conhecimento e com a possibilidade de transformar o meio em que viviam. Outros contextos fomentadores da interação foram as vivências estabelecidas a partir da mediação com os colegas e com pessoas mais experientes, além de situações constituídas a partir do desenvolvimento de conteúdos próximos à realidade social dos educandos.

Como sugestões de estudos futuros, têm-se a ampliação da pesquisa com outros tipos de recursos digitais e aplicativos específicos em outros níveis de ensino. Ainda, outra alternativa é a promoção do acesso às TIC aos alunos com alcance restrito destas, como forma de verificar os níveis de envolvimento em meio às possibilidades oferecidas pelos recursos.

A relação entre as TIC e os processos de ensino e de aprendizagem são uma realidade inevitável e devem ser caracterizados pela mediação entre docentes, aprendentes e os recursos tecnológicos, de forma estruturada e pedagogicamente organizada. Espera-se, portanto, que este estudo possa despertar novos anseios e inquietações, trazendo, sobretudo, contribuições para o contexto pedagógico aliado ao uso das TIC.

\section{Referências}


VII Congresso Brasileiro de Informática na Educação (CBIE 2018)

Anais do XXIV Workshop de Informática na Escola (WIE 2018)

Colaço, V. F. R. (2001). Interações em sala de aula: um estudo da atividade discursiva de crianças em séries iniciais. 2001. Tese (Doutorado em Educação) - Programa de Pós-Graduação em Educação, Universidade Federal do Rio Grande do Sul, Porto Alegre.

(2004). Processos interacionais e a construção de conhecimento e subjetividade de crianças. Psicologia: reflexão e crítica, v. 17, n. 3, p. 333-340.

David, P. B.(2010). Interações contingentes em ambientes virtuais de aprendizagem. 2010. 226 f. Tese (Doutorado em Educação) - Faculdade de Educação, Universidade Federal do Ceará, Fortaleza.

Frade, C. C.; Meira, L. (2012). Interdisciplinaridade na escola: subsídios para uma zona de desenvolvimento proximal como espaço simbólico. Educação em Revista, v. 28, n. 1 ,

Góes, M. C. (2001). A construção de conhecimentos e o conceito de zona de desenvolvimento proximal. In: MORTIMER, E. F.; SMOLKA, A. L. B. (Org.). Linguagem, cultura e cognição: reflexões para o ensino e a sala de aula. Belo Horizonte: Autêntica.

Lipponen, L. (2002) Exploring foundations for computer-supported collaborative learning. 2002. Disponível em: $<$ http://www.helsinki.fi/science/networkedlearning/texts/ lipponen2002.pdf $>$. Acesso em: 10 jan. 2018.

Meira, L. (1994). Análise microgenética e videografia: ferramentas de pesquisa em psicologia cognitiva. Temas em Psicologia, v. 2, n. 3, p. 59-71.

Meira, L.; Lerman, S. (2009). Zones of Proximal Development as fields for communication and dialogue. In: LIGHTFOOT, C. M. C. D.; LYRA, P. (Org.).Challenges and strategies for studying human development in cultural contexts. Roma: Firera Publishing.

Meira, L.; Spinillo, A. G. (2006). Psicologia cognitiva: cultura, desenvolvimento e aprendizagem. Recife: Universitária.

Nascimento, K. A. S.; Castro Filho, J. A.(2015). Aprendizagem móvel e suas tecnologias: uma revisão sistemática da literatura. In: Anais dos Workshops do Congresso Brasileiro de Informática na Educação. Congresso Brasileiro de Informática na Educação - CBIE, 2015. p. 721.

Resta, P; Laferrière, T. (2007). Technology in support of collaborative learning. Educational Psychology Review, v. 19, n. 1, p. 65-83.

Rodrigues, N.N. et al.(2011) Tecnologias de Informação e Comunicação Aplicadas à Terceira Idade. Workshop de Informática na Escola, Aracajú. In: Congresso Brasileiro de Informática na Educação- CBIE 2011, Aracaju.

Santiago, L.B.M. et al. (2016) O uso das Tecnologias Digitais na busca da superação do analfabetismo. Workshop Sobre Tecnologias Móveis Na Educação. In: Congresso Brasileiro de Informática na Educação- CBIE 2016, Uberlândia.

Silva, M. A.(2014) Trabalho colaborativo em rede no projeto Um Computador por Aluno (UCA): conhecimentos e práticas docentes. 2014. Tese (Doutorado em Educação) Faculdade de Educação, Universidade Federal do Ceará, Fortaleza. 
VII Congresso Brasileiro de Informática na Educação (CBIE 2018)

Anais do XXIV Workshop de Informática na Escola (WIE 2018)

Vygotsky, L. S. (1994).A formação social da mente. São Paulo: Martins Fontes.

Wertsch, James V. (2010). Second international interdisplinarity conference on perspectives and limits of dialogism in Mikhail Bakhtin. Educação e Pesquisa, São Paulo, v. 36, n. esp., p. 123-132. 